\title{
Inhibiting Interfacial Recombination Events in Dye-Sensitized Solar Cells using Self- Assembled Bilayers
}

\author{
Omotola O. Ogunsolu, ${ }^{a}$ Jamie C. Wang, ${ }^{\mathrm{b}}$ and Kenneth Hanson ${ }^{\mathrm{a}, \mathrm{b} *}$ \\ ${ }^{a}$ Materials Science and Engineering, Florida State University, Tallahassee, Florida \\ 32306, United States \\ ${ }^{b}$ Department of Chemistry and Biochemistry, Florida State University, Tallahassee, \\ Florida 32306, United States
}

*Corresponding Author: hanson@chem.fsu.edu 


\section{Contents}

1. Figure S1 and S2. Cell Assembly Apparatus ........................................Page S-3

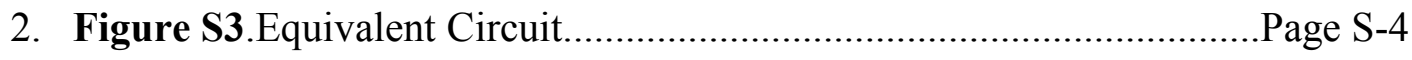

3. Figure S4. Absorption Spectra for $\mathrm{TiO}_{2}-\mathbf{N} 3$ and $\mathrm{TiO}_{2}-(\mathbf{X})-\mathrm{Zr}-\mathrm{N} 3 \ldots \ldots \ldots \ldots . . . \mathrm{Page} \mathrm{S}-4$

4. Table S1.Parameters from EIS fitting ……………………………........Page S-5

5. Figure S5. Comparison of $\mathrm{R}_{\mathrm{ct}}$ at different potentials ............................Page $\mathrm{S}-5$

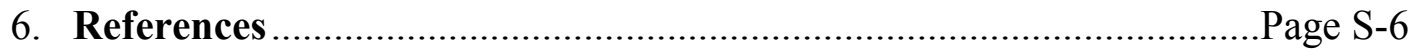


Cell Assembly Apparatus. Below is a photo (Figure S1) and a schematic (Figure S2) with suppliers and part numbers listed for the various components of our home built solar cell assembly apparatus. It is designed/programmed to apply consistent pressure and controlled heating to $150^{\circ} \mathrm{C}$ for 7 seconds.

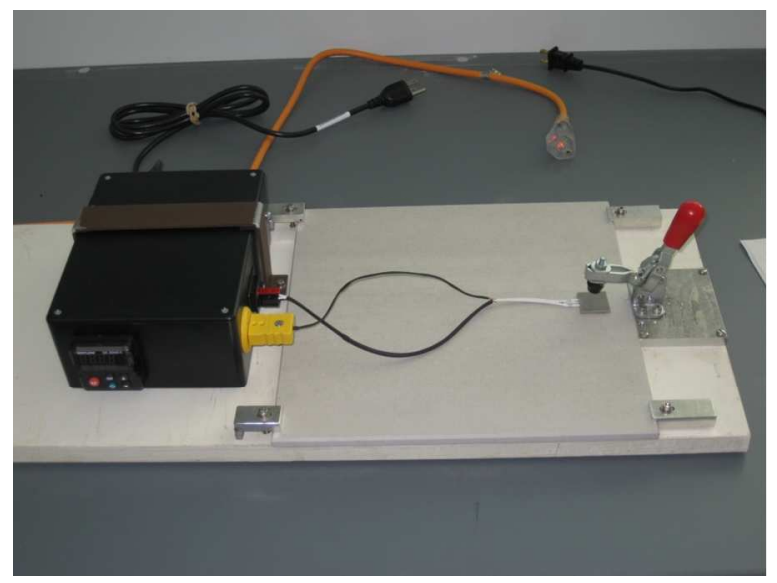

Figure S1. Photo of the home built cell sealing apparatus.

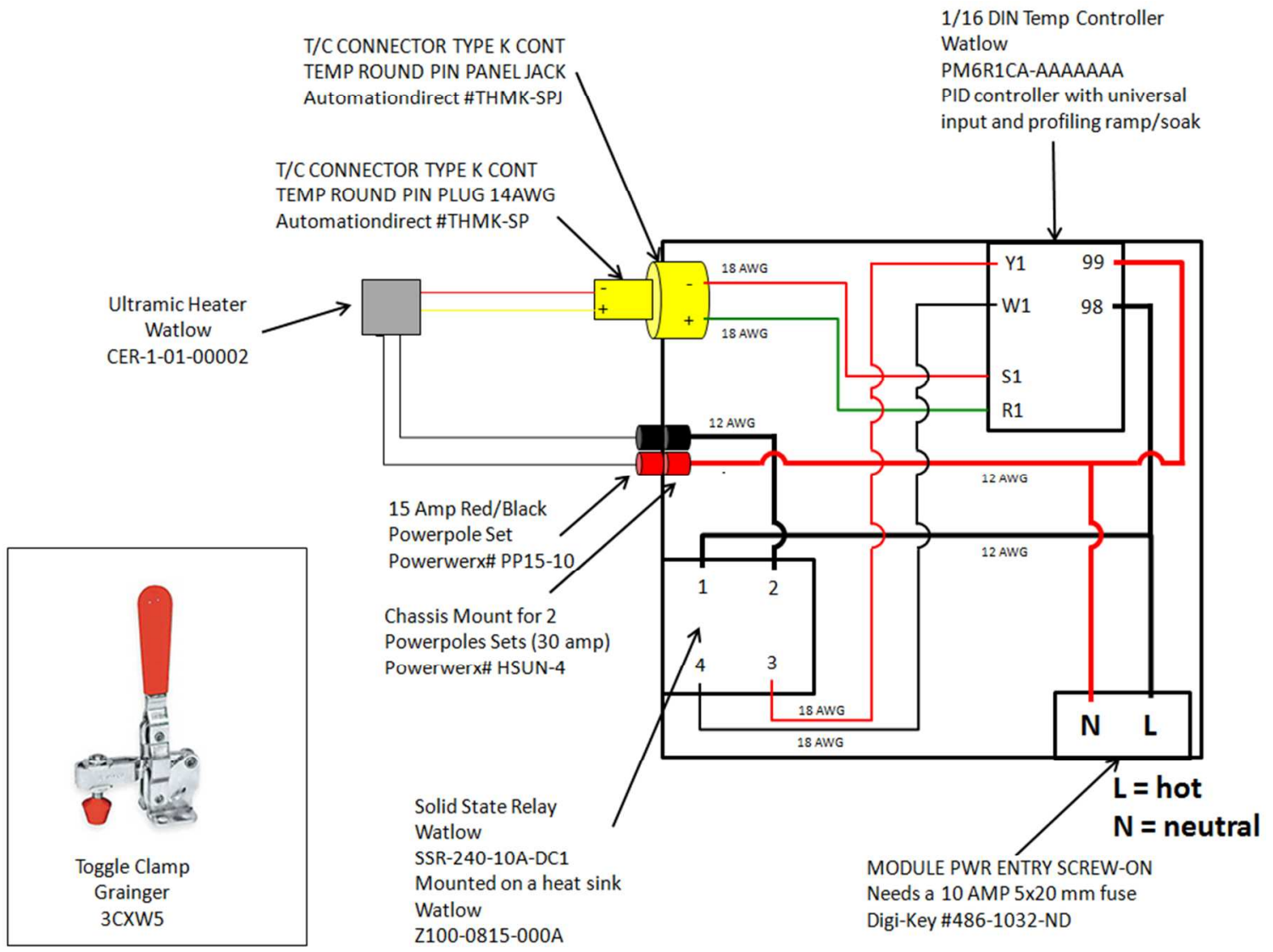

Figure S2. Schematic for the components of the home built cell sealing apparatus. 


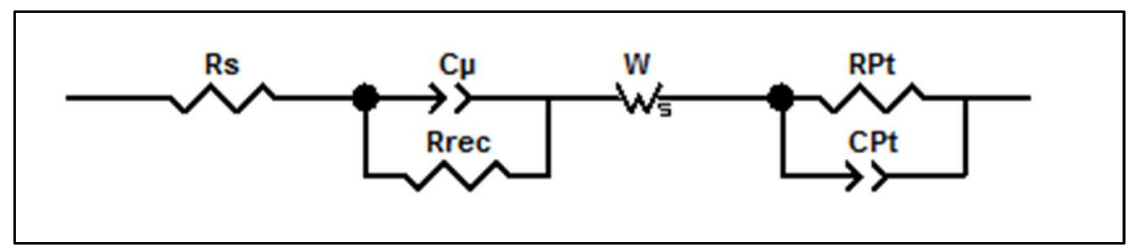

Figure S3. Equivalent circuit used to fit the electrochemical impedance data.

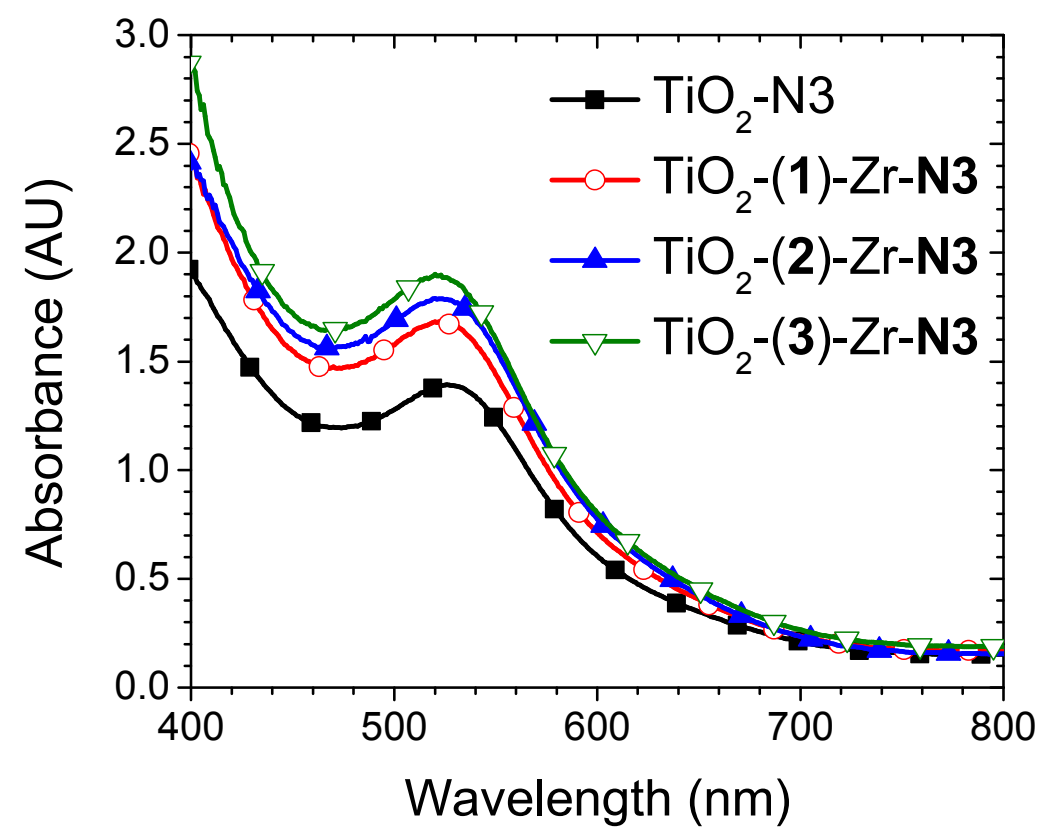

Figure S4. Absorption spectra for $\mathrm{TiO}_{2}-\mathrm{N} \mathbf{3}$ and $\mathrm{TiO}_{2}-(\mathrm{X})-\mathrm{Zr}-\mathrm{N} \mathbf{3}$. $(\mathrm{X}=\mathbf{1}, \mathbf{2}$ and $\mathbf{3})$ 
Table S1. Resistances, capacitances and other parameters obtained from fitting the Nyquist Plots with the equivalent circuit shown in Figure $\mathrm{S} 3\left(\mathrm{~V}=\mathrm{V}_{\mathrm{oc}}\right)$.

\begin{tabular}{|l|l|l|l|l|}
\hline & $\mathrm{TiO}_{2}-\mathbf{N 3}$ & $\mathrm{TiO}_{2}-(\mathbf{1})-\mathrm{Zr}-\mathrm{N3}$ & $\mathrm{TiO}_{2}-(\mathbf{2})-\mathrm{Zr}-\mathrm{N} 3$ & $\mathrm{TiO}_{2}-(\mathbf{3})-\mathrm{Zr}-\mathrm{N} 3$ \\
\hline $\mathrm{R}_{\mathrm{Pt}}(\Omega)$ & 2.5 & 2.3 & 2.4 & 1.6 \\
\hline $\mathrm{C}_{\mathrm{Pt}}\left(\times 10^{-6} \mathrm{~F}\right)$ & 4.0 & 3.5 & 3.4 & 4.9 \\
\hline $\mathrm{R}_{\mathrm{rec}}(\Omega)$ & 19.1 & 32.5 & 34.5 & 46.5 \\
\hline $\mathrm{C}_{\mu}\left(\times 10^{-4} \mathrm{~F}\right)$ & 6.7 & 9.8 & 11.6 & 13.6 \\
\hline$k_{\mathrm{eff}}=\omega_{\mathrm{k}}\left(\mathrm{s}^{-1}\right)^{a}$ & 78.3 & 31.5 & 25.0 & 15.8 \\
\hline$\tau_{\mathrm{eff}}(\mathrm{ms})^{b}$ & 12.8 & 31.8 & 39.9 & 63.3 \\
\hline $\mathrm{R}_{\mathrm{w}}(\Omega)^{c}$ & 9.8 & 8.5 & 10.2 & 6.9 \\
\hline$\omega_{\mathrm{d}}\left(\mathrm{s}^{-1}\right)$ & 152 & 120.4 & 84.8 & 107 \\
\hline $\mathrm{D}_{\mathrm{efff}}\left(\times 10^{-5} \mathrm{~cm}^{2} / \mathrm{s} \Omega\right)^{d}$ & 2.4 & 1.9 & 1.4 & 1.7 \\
\hline $\mathrm{L}_{\mathrm{n}}(\mu \mathrm{m})^{e}$ & 5.6 & 7.8 & 7.4 & 10.4 \\
\hline $\mathrm{n}_{\mathrm{s}}\left(\times 10^{18} / \mathrm{cm}^{3}\right)^{f}$ & 1.1 & 1.6 & 1.9 & 2.2 \\
\hline
\end{tabular}

a) $k_{\text {eff }}=2 \pi f$, b) $k_{\text {eff }}=1 / \tau_{\text {eff }}$, c) $\left.\mathrm{R}_{\text {rec }} / \mathrm{R}_{\mathrm{w}}=\omega_{\mathrm{d}} / \omega_{\mathrm{k}}, \mathrm{d}\right) \mathrm{D}_{\text {eff }}=\left(\mathrm{R}_{\mathrm{rec}} / \mathrm{R}_{\mathrm{w}}\right) \mathrm{L}^{2} \mathrm{k}_{\text {eff }}$, e) $\mathrm{L}_{\mathrm{n}}=\left(\mathrm{D}_{\text {eff }} \times\right.$ $\left.\left.\tau_{\text {eff }}\right)^{1 / 2}, \mathrm{f}\right) \mathrm{n}_{\mathrm{s}}=\left(\mathrm{k}_{\mathrm{B}} \mathrm{TL}\right) /\left(\mathrm{q}^{2} \mathrm{AR}_{\mathrm{w}} \mathrm{D}_{\text {eff }}\right)$ where $\mathrm{A}$ is electrode area, $\mathrm{T}$ is temperature and $\mathrm{L}$ is film thickness. ${ }^{1,2}$

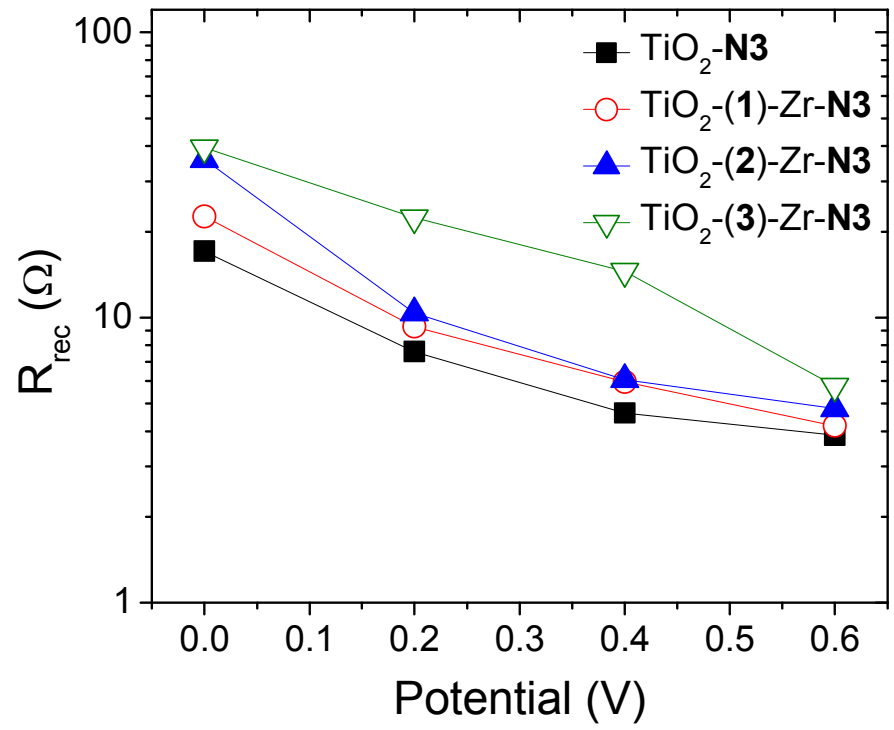

Figure S5. Comparison of $\mathrm{R}_{\mathrm{ct}}$ for $\mathrm{TiO}_{2}-\mathrm{N3}$ and $\mathrm{TiO}_{2}-(\mathrm{X})-\mathrm{Zr}-\mathrm{N} \mathbf{3}(\mathrm{X}=\mathbf{1}, \mathbf{2}$ and $\mathbf{3})$ at different potentials ( $\mathrm{V}$ vs $\left.\mathrm{V}_{\mathrm{oc}}\right)$. 


\section{References}

1. Adachi, M.; Sakamoto, M.; Jiu, J. T.; Ogata, Y.; Isoda, S., Determination of Parameters of Electron Transport in Dye-sensitized Solar Cells Using

Electrochemical Impedance Spectroscopy. J. Phys. Chem. B 2006, 110, 13872-13880.

2. Cisneros, R; Beley, M; Fauvarque, J; Lapicque, F., Investigation of Electron Transfer Process Involved in DSSC's by Wavelength Dependent Electrochemical Impedance Spectroscopy( $\lambda$-EIS) Electrochim. Acta 2015, 171 49-58. 